\title{
Molybdenum oxo-imido aryloxide complexes: oxo analogues of olefin metathesis catalysts.
}

\author{
Warren B. Cross, James C. Anderson, * Claire S. Wilson and Alexander J. Blake
}

School of Chemistry, University of Nottingham, NG7 2RD, UK

j.anderson@nottingham.ac.uk

Index

Page

Copies of $1 \mathrm{H}$ and 13C NMR spectra:

1

$1 \mathrm{H} .$. S2

$13 \mathrm{C}$ S3

2

$1 \mathrm{H}$. S4

$13 \mathrm{C}$ .S5

3

$1 \mathrm{H}$. S6

$13 \mathrm{C}$ S7 


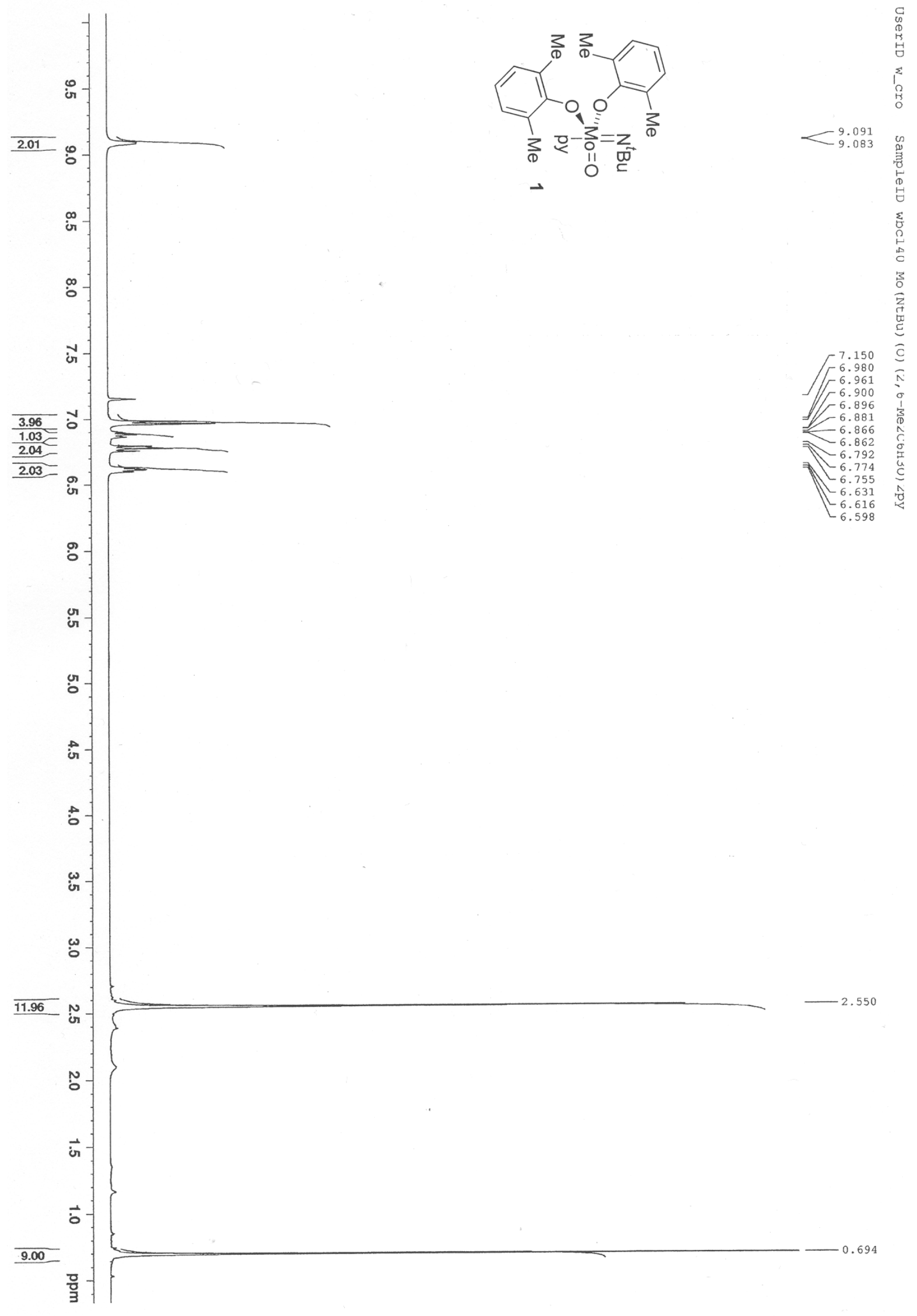




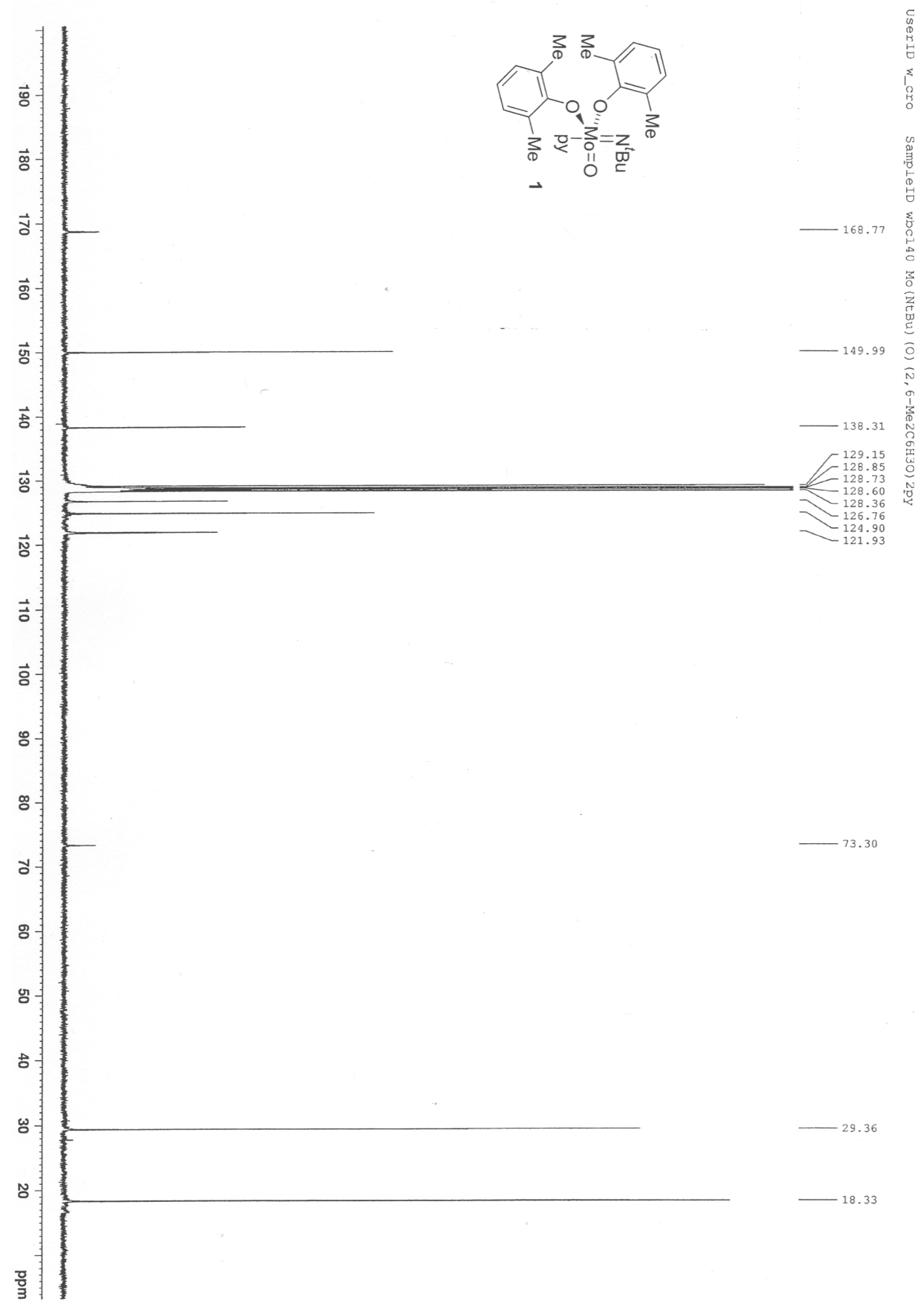




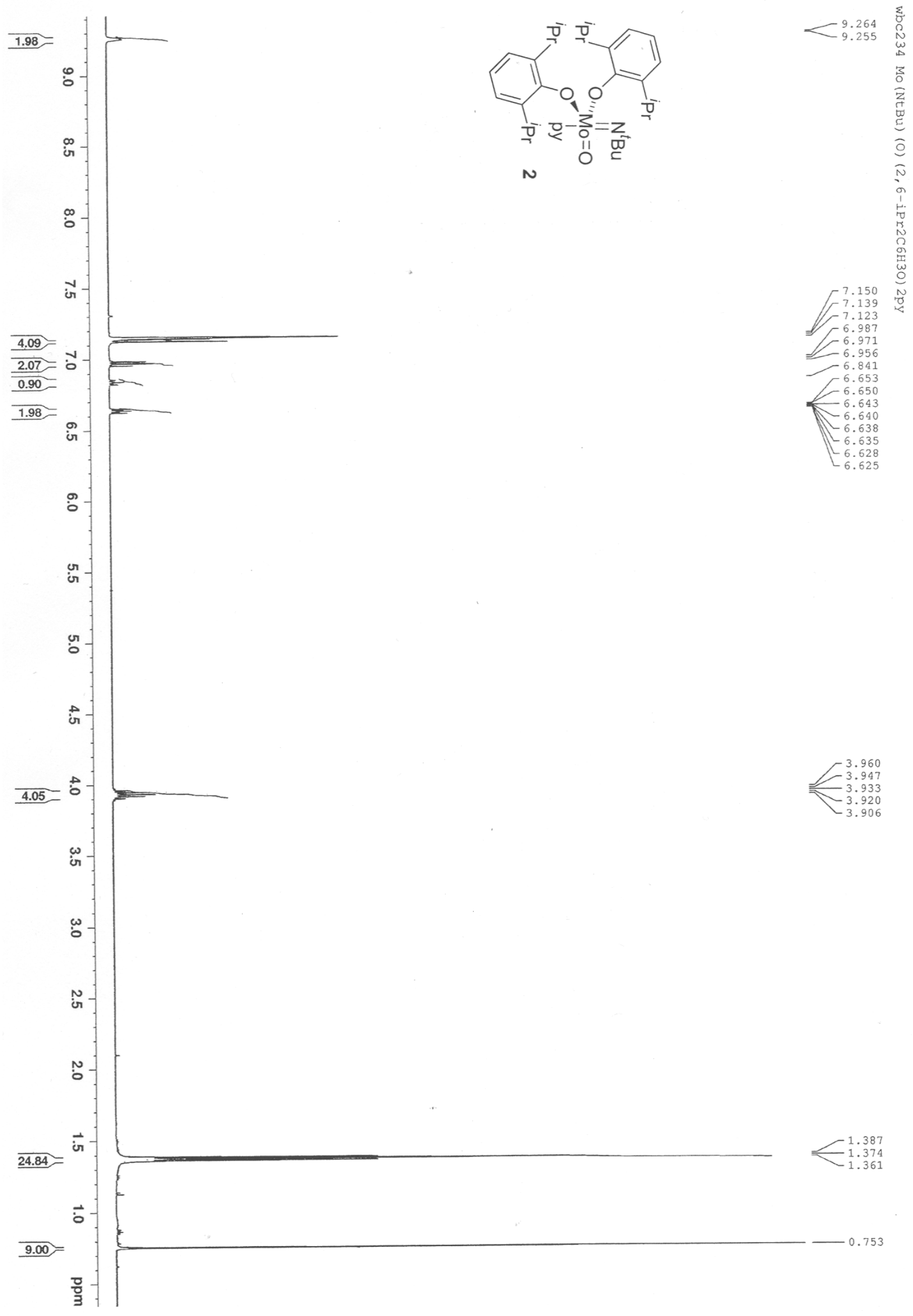




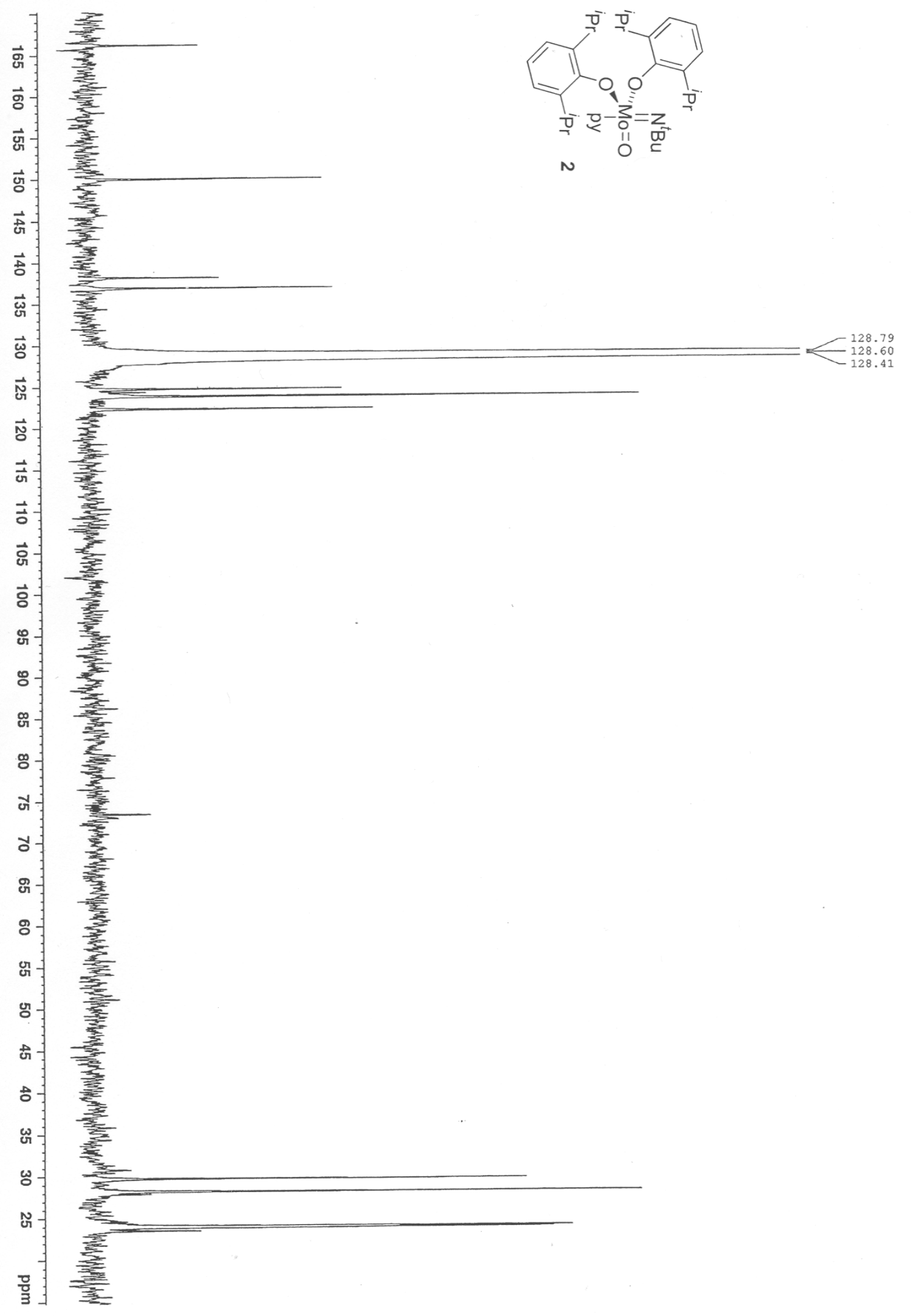




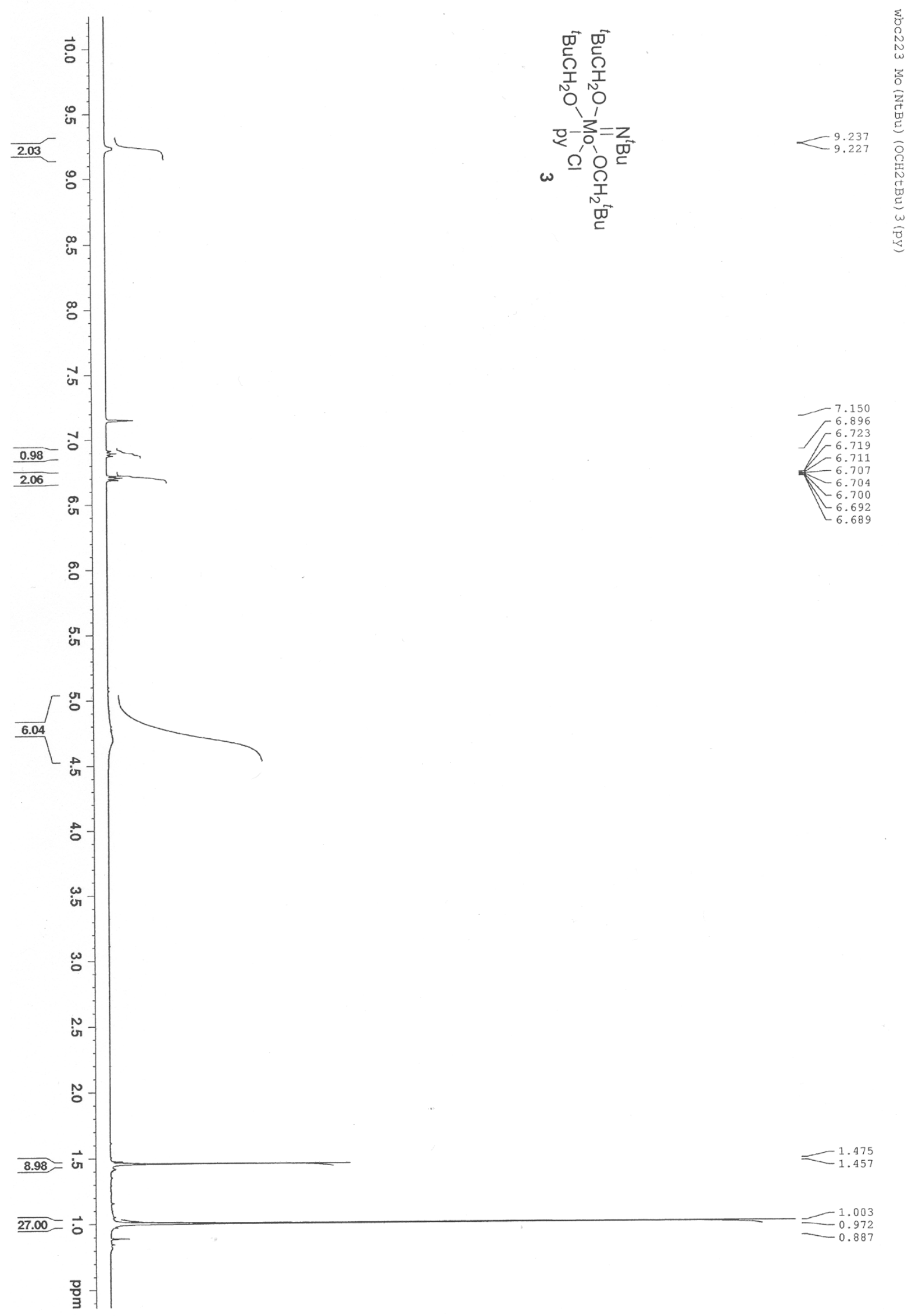




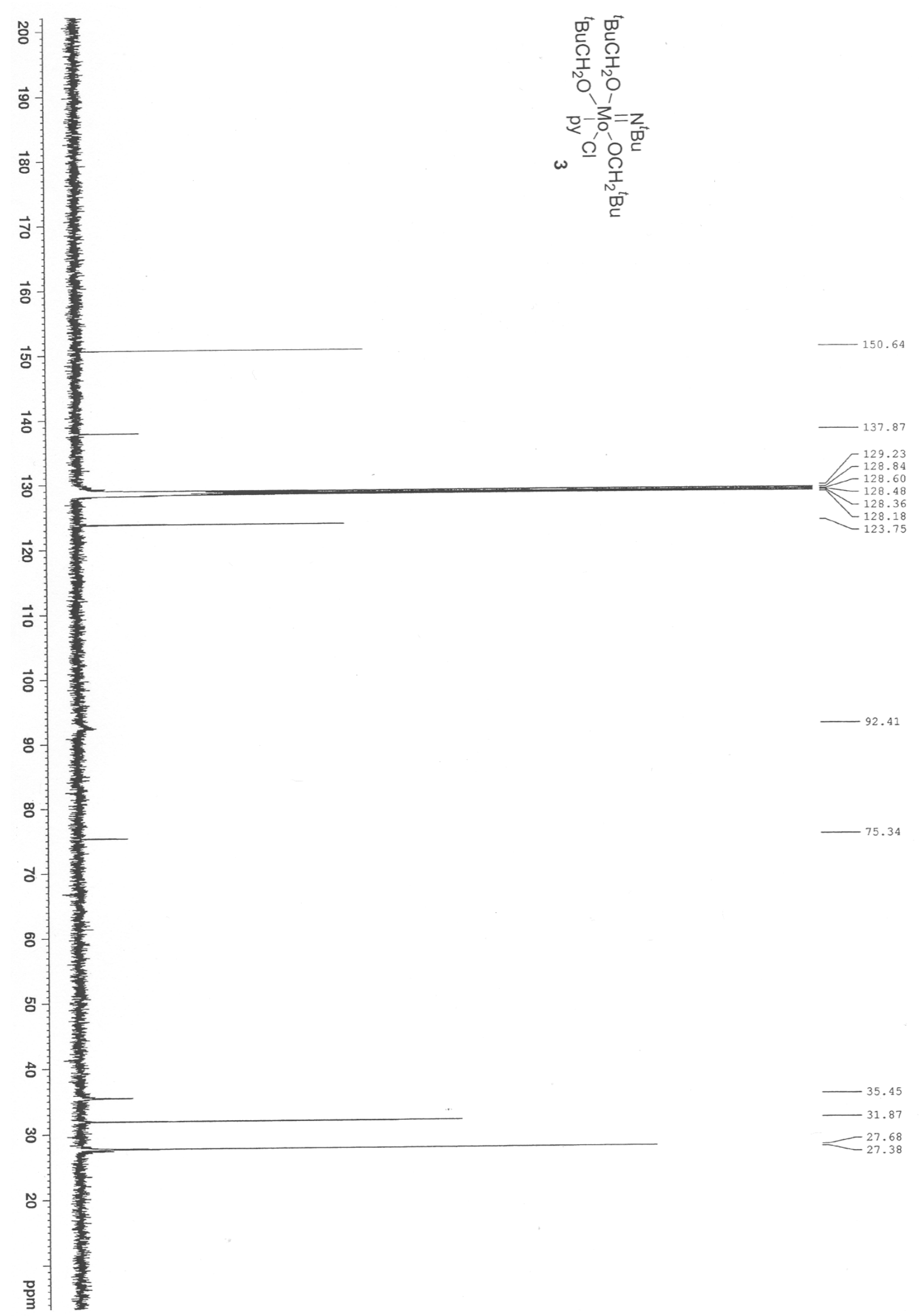

